University of Wollongong

Research Online

Faculty of Engineering - Papers (Archive)

Faculty of Engineering and Information

Sciences

$1-1-2009$

\title{
Superconducting magnetic energy storage systems for power system applications
}

Danny Soetanto

University of Wollongong, soetanto@uow.edu.au

K.W.E Cheng

The Hong Kong Polytechnic University

Follow this and additional works at: https://ro.uow.edu.au/engpapers

Part of the Engineering Commons

https://ro.uow.edu.au/engpapers/522

\section{Recommended Citation}

Soetanto, Danny and Cheng, K.W.E: Superconducting magnetic energy storage systems for power system applications 2009, 377-380.

https://ro.uow.edu.au/engpapers/522

Research Online is the open access institutional repository for the University of Wollongong. For further information contact the UOW Library: research-pubs@uow.edu.au 


\section{Superconducting Magnetic Energy Storage Systems for Power System Applications}

\author{
D. Sutanto, Senior Member, IEEE \\ School of Electrical, Computer \\ and Telecommunications Engineering \\ University of Wollongong \\ Wollongong, Australia \\ soetanto@uow.edu.au
}

\author{
K.W.E. Cheng \\ Department of Electrical Engineering \\ Hong Kong Polytechnic University \\ Hung Hom, Hong Kong, China \\ eeecheng@polyu.edu.hk
}

\begin{abstract}
Advancement in both superconducting technologies and power electronics led to High Temperature Superconducting Magnetic Energy Storage Systems (SMES) having some excellent performances for use in power systems, such as rapid response (millisecond), high power (multi-MW), high efficiency, and fourquadrant control. This paper provides a review on SMES applications to power systems.
\end{abstract}

\section{Keywords-smes; power system; energy storage; superconductor}

\section{INTRODUCTION}

SMES is an energy storage system that stores energy in the form of dc electricity by passing current through the superconductor and stores the energy in the form of a dc magnetic field. The conductor for carrying the current operates at cryogenic temperatures where it becomes superconductor and thus has virtually no resistive losses as it produces the magnetic field. Consequently, the energy can be stored in a persistent mode, until required. In general, an SMES system consists of four parts, which are the superconducting coil with the magnet (SCM), the power conditioning system (PCS), the cryogenic system (CS), and the control unit (CU), as shown in Fig. 1.

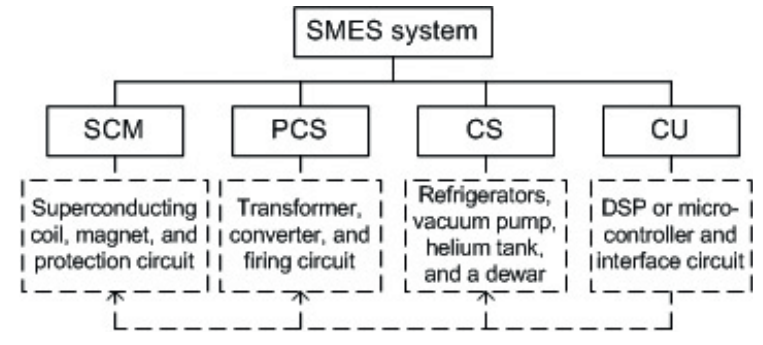

Figure 1. Block diagram of an SMES system.

A low Temperature SMES requires liquid hydrogen for its operation, which makes it expensive to operate, particularly with CS. With the availability of a High Temperature superconducting coil, only liquid nitrogen is required, which is readily available and much cheaper than liquid hydrogen. With higher temperatures come not only reduced refrigeration costs but also enhanced reliability.

Advances in both superconducting technologies and power electronics led to SMES systems having some excellent performances particularly for use in power systems, such as rapid response (millisecond), high power (multi-MW), high efficiency, and four-quadrant control. Consequently, SMES systems will be able to store energy more efficiently than any conventional energy storage systems such as chemical batteries, flywheels, or hydro-pumped storage. SMES is expected to become the next generation technology for storing electrical energy. SMES systems can offer flexible, reliable, and fast acting active and reactive power compensation. Furthermore, the integrated system appears to be feasible for some utility applications at a cost that is competitive with other technologies. The purpose of this paper is to provide a review of SMES applications to power systems.

\section{DEVELOPMENT OF SMES APPLICATIONS}

Up to now, reported applications of SMES may be classified into two kinds, which are power system applications [1-22] and pulse power application [23]. Pulse magnets of SMES, can be used to smooth voltage sags and to mitigate flicker [23].

In recent years constraints forced by the environment, right of way and energy costs have resulted in power systems operating with considerably reduced stability margins. Consequently, modern power systems depend strongly on stabilizing devices to keep reliable and stable operation. These devices should provide sufficient damping in the system, during the transient period following a system disturbance, such as line switching, load changes and fault clearance. To avoid collapse of the system due to loss of synchronism or voltage instability, countermeasures such as power system stabilizers, optimal turbine governor control systems and phase shifters have been used.

The application of the SMES system to a power system was first proposed in 1969 [1]. That idea is to charge the superconducting magnet with the surplus generation of the basic load units during off-peak time, and to discharge to the ac power system during peak time. The first superconducting power-grid application to achieve full commercial status of SMES was in 1981; it was located along the $500 \mathrm{kV}$ Pacific Intertie that interconnects California and the Northwest [2]. That practical application of SMES demonstrated the feasibility of SMES to improve transmission capacity by damping inter-area modal oscillations. Since that time, much 
attention has been paid to SMES applications to power systems. Many studies had been made and prototypes were developed for installing SMES. To boost the development of SMES applications, some papers summarized previous researches on SMES technology and reported ongoing ones. A survey of the technology of SMES was made in [1]. At the same time, the authors of [1] also proposed some power system applications of SMES. Reference [2] summarized the results of studies of SMES to improve transmission system performance. Luongo [3] reviewed a history of SMES development in the US and summarized ongoing SMES developments in US, Europe, and Japan. Furthermore, the paper gave the cost estimation of SMES systems and discussed markets of SMES. Later, Karasik et al [4] gave a review of technical and cost consideration for SMES applications to power utility. Buckles et al [5] gave an overview of the historical perspective and technology status of SMES in the world, and described practical applications of SMES systems to power systems. A number of reported studies explored and investigated feasible SMES applications to power systems. These applications can basically be classified into two aspects: one is system stability enhancement and the other is power quality improvement.

\section{APPLICATIONS FOR POWER SYSTEM STABILITY IMPROVEMENT}

\section{A. Reduction of System Oscillations}

Low-frequency oscillations $(0.5-1 \mathrm{~Hz})$ following a system disturbance in a weak power system can lead to power system dynamic stability limitations. Power transfers are often limited to prevent growing oscillations from occurring, following the loss of a single major transmission line or generator. The transmission capacity can be increased by actively providing damping against these oscillations. SMES can actively reduce these system oscillations through modulation of both real power and reactive power and hence it can be much more effective, and smaller in size, than other technologies. Fig. 2 presents a schematic diagram of a typical power transmission system with an SMES unit for reducing system oscillations. SMES can control the active power Ps from SMES to suppress the oscillations of the angular velocity $\omega$ of the generator or the power flow $\mathrm{Pt}$, and controls the reactive power Qs to suppress the fluctuation of the line voltage of the bus to which the SMES is connected.

Karasik et al [4] described a method to modulate active and reactive power of the SMES unit in a model power transmission system, and verified the effect of power system stabilizing control by using SMES. Rabbani et al [6] described a fuzzy control strategy for the SMES unit to damp any kind of disturbance in the power system.

\section{B. Boosting Voltage Stability and Improving Voltage Sag}

Voltage instability can occur when there is a major loss of generation or heavily loaded transmission lines and there is insufficient reactive power support to maintain voltages.

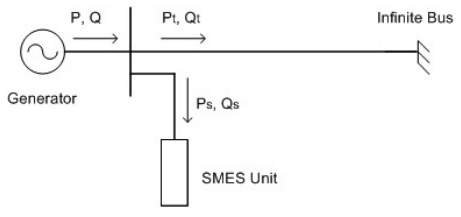

Figure 2. A typical SMES unit connection whose active and reactive power can be modulated to reduce oscillation.

SMES is effective in mitigating dynamic voltage instability by providing real power and reactive power at the load end supplanting the loss of generation or a major transmission line. By having a static power generator at the load end, which can provide both active and reactive power will allow reduction in the reactive power loss in the transmission line as well as requiring less reactive power support from other generators, SMES can stabilize the system long enough to allow generators or other reactive power sources to come on line and prevent voltage instability. Further SMES can also be used to support a transient voltage dip lasting for 10-20 cycles due to a major disturbance on the power system e.g. lightning. The SMES can be connected in series with the transmission line to dynamically add or subtract $\Delta \mathrm{V}$ to counter the voltage $\mathrm{sag} / \mathrm{swell}$ in the power system. Voltage sag and swell in the power system is particularly harmful to sensitive loads such as paper, glass or electronic plants.

\section{APPLICATIONS FOR POWER QUALITY IMPROVEMENT}

\section{A. Offering Spinning Reserve}

In case a major generating unit or major transmission line is forced out of service, a specified number of generation devices must be kept unloaded as 'spinning reserve'. Most operating guidelines require that this spinning reserve can be as much as $7 \%$ of the system load or largest single contingency. Since SMES can store a significant amount of energy, with sufficient numbers of SMES, they can provide enough 'spinning reserve' to satisfy the requirement until gas turbine generators can be brought online [2].

\section{B. Enhancing FACTS Performances}

SMES systems can be configured to offer energy storage for FACTS (Flexible AC Transmission System) devices. FACTS inverters and PCSs of SMES systems are configured in very similar ways. FACTS devices, however, operate with the energy available from the electric grid and usually use capacitor in the DC of the converter. SMES can enhance FACTS performance by providing active power in addition to reactive power through the DC bus. Reference [7] presented a control scheme for power system stabilization, considering the combination of an SMES and high-speed phase shifter to be a unified power system controller. Their experiment verified that the developed apparatus with the proposed control scheme is effective for the stabilization of a long-distance bulk power transmission system even through it is located far from the generator. Ribeiro et al [9] discussed the power quality benefits for transmission systems by integrating a FACTS controller with SMES. An SMES coil is incorporated into a voltage source inverter based STATCOM to damp dynamic oscillations in power systems. Their studies indicated that, 
depending on the location of the STATCOM using SMES, simultaneous control of real and reactive power can improve the system stability and power quality of a transmission grid. Furthermore, the STATCOM using SMES connected to a bus near the generator (such as the location of bus A shown in Fig. 3 can be very effective in damping electromechanical transient oscillations caused by a three-phase fault [9]).

\section{Balancing Fluctuating Loads}

SMES is a promising device for balancing fluctuating active and reactive power from various loads such as industrial manufacturing plants, nuclear fusion power plants, and substations of a high-speed railway system. Fig. 4 depicts a typical SMES control system to compensate for fluctuating loads, located close to the customer end. The source can be controlled to only provide the constant components of the load power. The SMES will be controlled to provide the fluctuating components of the load. Without this power compensating system, voltage fluctuations will exist in the source voltage. Further, with this system, the fluctuating component of the source side can be also be compensated by releasing or absorbing energy of the SMES. References [10-12] proposed control strategies of the SMES system to suppress voltage fluctuation caused by disturbing loads. The results from both simulation and lab experiments demonstrated that an SMES system installed close to the power consumer end can be used to counter load power fluctuations by using the fuzzy control strategy [11]. Reference [13] developed an SMES system for compensation of power required to control unstable plasma in the International Thermonuclear Experimental Reactor system. Ise et al [14] proposed that the SMES system be utilized to compensate for fluctuating power from a high intensity synchrotron. It can absorb the fluctuation of active and reactive power caused by charging and discharging the synchrotron magnet.

\section{Decreasing Area Control Error}

When power is scheduled between utility in a control area, it is important that the actual net power is closely consistent with the scheduled power. Unfortunately when generators are ramped up in one control area and down in the receiving control area to send power, the system load can change and this results in an error in the actual power delivered. This area control error (ACE) can give rise to inefficient use of generation. SMES can be designed with appropriate controls to inject power to reduce this error and ensure that generation is efficiently used and power schedules are met. Reference [16] presented the results of a study on a small-capacity SMES system to supply sudden power requirements of a real power load. The ACE is used to control the SMES, when both load and SMES are connected in parallel at the generator terminal. The SMES is ready for generation or load control when the expected current in the SCM is reached. The variation in the ACE is sensed and used to control the SMES voltage by altering the duty cycle of the chopper. During sudden loading of the power system, the generator cannot pick up the load due to its inertia, so the ACE will be negative, and the SMES will discharge.

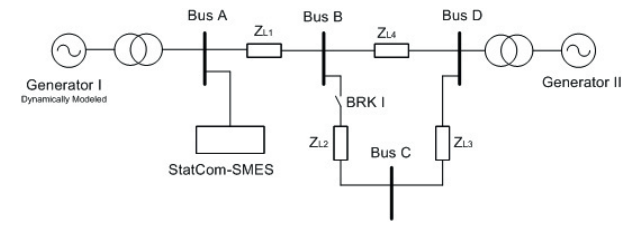

Figure 3. Configuration to improve FACTS in an equivalent two-machine system.

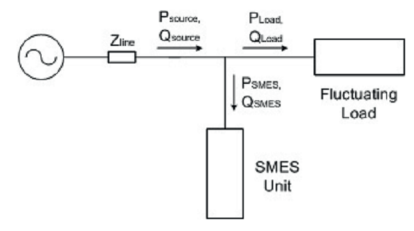

Figure 4. A typical system with SMES for balancing fluctuating load application.

\section{E. Load Leveling}

The energy with highest cost is usually produced under peak load conditions. Load leveling is implemented by storing energy during off-peak periods and then returning energy on peak. This benefit is realized when SMES gains credit for both converting low-cost energy into higher value energy and its ability to put off the acquisition of high-cost generating resources. SMES can have a large net present worth when it can replace the need to acquire combustion turbine units of similar capacity. The idea of SMES for load leveling was first proposed by Ferrier [1].

\section{F. Defending Critical Loads by Back-up Power Supply}

SMES can provide ride-through capability and smooth out disturbances on power systems that would otherwise interrupt sensitive customer loads. When momentary disturbances such as transmission line flashovers or lightning strikes occur, power can be lost if the transmission line trips, or voltages can dip. SMES has very fast response and can inject real power in less than one power cycle to protect important customers from losing power. Reference [15] developed a successful commercial application of micro-SMES technology to improve the power quality for critical loads. The most important characteristic of the developed micro-SMES system is its ability to completely supply any load connected to it during a short system disturbance such as a voltage sag caused by a remote fault, a momentary interruption caused by lighting or a tree climb, or any supply discontinuity during a load transfer between two available power sources. Kalafala et al [16] proposed an SMES system to protect critical industrial and military loads against voltage sags and interruptions, as well as to provide continuous power conditioning. Reference [17] presented an investigation of an SMES system for $15 \mathrm{kV}$ substation applications. Their studies indicated that an SMES system with the ride-through capacity of $1 \mathrm{sec}$ may be used for protection of all critical loads connected to a $15 \mathrm{kV}$ class utility bus and an SMES system with a ride-through capacity of at least $2 \mathrm{sec}$ is suitable for the protection of distributed critical loads connected to the customer's $15 \mathrm{kV}$ load bus. Protection of distributed critical loads by using SMES was also proposed by Aware and Sutanto [18], which also suggested a two-stage 
dc bus voltage operation by using the hysteresis control to regulate the SMES charging to extend the support time to critical loads during a short-term disturbance in the distribution network [18]. Chu and co-workers [12] investigated the performances of SMES systems as a UPS. They developed a control algorithm for the UPS application. These have been successfully tested by both simulation and the experiment.

\section{G. Balancing Power System Asymmetries}

Voltage asymmetry is very common in the operation of power systems because asymmetrical faults, single-phase load, unequal capacitance between line and ground, asymmetrical loads, and incomplete transposition of transmission line are unavoidable. Asymmetrical voltages will increase the loss of the transformer and transmission line, decrease the output power of transformer, reduce the efficiency of motors, affect the operation of critical load, and even endanger the safety of equipment. In addition, nonlinear loads and single-phase loads will cause harmonic and asymmetrical currents, which can result in more losses in distribution systems and non-normal operations of other devices. SMES systems can be used to balance asymmetrical currents and voltages. References [1922] described the compensation of harmonics and negative sequence components in line current and voltage by using an SMES system. Such an SMES system provides sinusoidal and balanced voltage and eliminates current harmonics and unbalances in three-phase lines of the distribution system.

\section{DiscussiOnS AND SUGGESTIONS}

SMES systems have been reported to have a number of useful applications to power systems. However, because of high cost and large investment of SMES systems, most of the reported studies are implemented through computer simulations or in laboratories. There are only a few cases of practical application. With advancements in power electronics technologies, cryogenics and reductions in the cost of superconductor and power components, more effort should be launched into practical applications of SMES to power systems. Also, practical SMES systems have small capacities. Hence, efficient control strategies that are used to integrate small ratings of SMES systems at various locations or to optimize allocations of these small ratings of SMES systems should be developed, in order to enhance the stability of power systems and to improve power quality. In addition, PCSs with large ratings and low harmonics should be developed through new circuit topologies, and control methods being suitable for large capacities of SMES systems. Development of SMES systems with many purposes for power systems is also needed. Such SMES systems may be implemented through the integration of various control strategies and the optimization of PCS configurations. This will enhance the ratio of performance versus cost for SMES systems, and consequently accelerate practical applications of SMES to power systems.

\section{REFERENCES}

[1] C. S. Hsu and W. J. Lee, "Superconducting magnetic energy storage for power system applications," IEEE Trans. Ind. Appl., vol. 29, pp. 990996, 1992.
[2] W. V. Torre and S. Eckroad, "Improving power delivery through the application of superconducting magnetic energy storage (SMES)," Proc. 2001 IEEE PES Winter Meeting, vols. 1-3, pp. 81-87, 2001.

[3] C. A. Luongo, "Superconducting storage systems: an overview," IEEE Trans. Magn., vol. 32, pp. 2214-2223, 1996.

[4] V. Karasik, et al., "SMES for power utility applications: a review of technical and cost considerations," IEEE Trans. Appl. Supercond., vol. 9, pp. 541-546, 1999.

[5] W. Buckles and W. Hassenzahl, "Superconducting magnetic energy storage," IEEE Power Eng. Rev., vol. 20, pp. 16-20, May 2000.

[6] M. G. Rabbani, J. B. X. Devotta, and S. Elangovan, "Fuzzy controlled SMES unit for power system application," Proc. Int. Conf. on Energy Management and Power Delivery, EMPD, vol. 1, pp 41-46, 1998.

[7] D. Kamolyabutra, Y. Mitani, T. Ise, and K. Tsuji, "Experimental study on power system stabilizing control scheme for the SMES with solidstate phase shifter (SuperSMES)," IEEE Trans. Appl. Supercond., vol. 9 pp. 326-329, 1999.

[8] A. Arsoy, Y. Liu, P. F. Ribeiro, and F. Wang, "Power converter and SMES in controlling power system dynamics," 2000 IEEE Industry Applications Conf., vol. 4, pp. 2051-2057, 2000.

[9] P. F. Ribeiro, A. Arsoy, and Y. L. Liu, "Transmission power quality benefits realized by a SMES-FACTS controlle," 9th Int. Conf. on Harmonics and Quality of Power, vols. I, pp. 307-312, 2000.

[10] H. C. Tay and M. F. Conlon, "Development of a SMES system as a fluctuating load compensator," IEE Proc. Gener. Transm. Distrib., vol. 145 , pp. 700-708, 1998.

[11] S. Funabiki, T. Yorioka and T. Fujii, "An experiment of fuzzy control for leveling load power fluctuations using an SMES simulator," 33rd IEEE IAS Annual Meeting, vol. 2, pp. 1269-1274, 1998.

[12] X. Chu, X. H. Jiang, Y. C. Lai, X. Z. Wu and W. Liu, "SMES control algorithms for improving customer power quality," IEEE Trans. Appl. Supercond., vol. 11, pp. 1769-1772, 2001.

[13] T. Ise, "Studies on power conditioning system for SMES in ITER," IEEE Trans. Appl. Supercond., vol. 11, no. 1, pp. 1896-1899, 2001.

[14] T. Ise et al, "Magnet power supply with power fluctuation compensating function using SMES for high intensity synchrotron," IEEE Trans. Appl. Supercond., vol. 13, pp. 1814-1817, 2003.

[15] J. Lamoree, L. Tang, C. DeWinkel and P. Vinett, "Description of a Micro-SMES for protection of critical customer facilities," IEEE Trans. Power Deliv., vol. 9, pp. 984-991, 1994.

[16] A. K. Kalafala, et al., "Micro superconducting magnetic energy storage (SMES) system for protection of critical industrial and military loads," IEEE Trans. Magn., vol. 32, pp. 2276-2279, 1996.

[17] M. Parizh, A. K. Kalafala and R. Wilcox, "Superconducting magnetic energy storage for substation applications," IEEE Trans. Appl. Supercond., vol. 7, pp. 849-852, 1997.

[18] M. V. Aware and D. Sutanto, "SMES for protection of distributed critical loads," IEEE Trans. Power Deliv., vol. 19, pp. 1267-1275, 2004.

[19] T. Ise, J. Ishii and S. Kumagai, "Compensation of harmonics and negative components in line current and voltage by a SuperSMES," IEEE Trans. Appl. Supercond., vol. 9, pp. 334-337, 1999.

[20] D. Casadei, G. Grandi, U. Reggiani, G. Serra and A. Tani, "Behavior of a power conditioner for $\mu$-SMES systems under unbalanced supply voltages and unbalanced loads," Proc. IEEE Int. Symp. on Industrial Electronics, vol. 2, pp. 539-544, 1999.

[21] H. C. Tay and M. F. Conlon, "Development of an unbalanced switching scheme for a current source inverter", IEE Proc. Gener. Transm. Distrib., vol. 147, pp. 23-30, 2000.

[22] J. Yu, X. Duan, Y. Tang, and P. Yuan, "Control scheme studies of voltage source type superconducting magnetic energy storage (SMES) under asymmetrical voltage," IEEE Trans. Appl. Supercond., vol. 12, pp. 750-753, 2002.

[23] K. P. Juengst and H. Salber, "Fast SMES for generation of high power pulse,” IEEE Trans. Magn., vol. 32, pp. 2272-2275, 1996. 